\title{
DETERMINAÇÃO ESPECTROFOTOMÉTRICA DE CITRATO DE SILDENAFIL EM FORMULAÇÕES FARMACÊUTICAS
}

\author{
Patrícia Los Weinert, Leonardo Pezza e Helena Redigolo Pezza* \\ Instituto de Química, Universidade Estadual Paulista, CP 355, 14801-970 Araraquara - SP, Brasil
}

Recebido em 25/5/07; aceito em 11/10/07; publicado na web em 2/4/08

\begin{abstract}
SPECTROPHOTOMETRIC DETERMINATION OF SILDENAFIL CITRATE IN PHARMACEUTICAL FORMULATIONS. This paper describes a simple and rapid spectrophotometric method for quantitative determination of sildenafil citrate based on its reaction with p-chloranil accelerated by hydrogen peroxide, producing a stable purple compound $\left(\lambda_{\max }=535 \mathrm{~nm}\right)$. In the absence of peroxide this reaction is very slow. The experimental conditions were optimized by using response surface methodologies. Beer's law is obeyed in a concentration range of $8.52 \times 10^{-5}-1.70 \times 10^{-3} \mathrm{~mol} \mathrm{~L}^{-1}(\mathrm{r}=0.999)$. The detection limit was $1.96 \times 10^{-5} \mathrm{~mol} \mathrm{~L}^{-1}$. The method was successfully applied for the determination of sildenafil citrate in medicines with good accuracy and precision.
\end{abstract}

Keywords: sildenafil citrate; p-chloranil; spectrophotometry.

\section{INTRODUÇÃO}

Citrato de sildenafil é quimicamente designado como citrato de 1-[[3-(6,7-diidro-1-metil-7-oxo-3-propil-1H-pirazol-[4,3d]pirimidin-5-il)-4-etóxifenil]sulfonil]-4- metilpiperazina ${ }^{1}$ (Figura 1). É o princípio ativo do Viagra ${ }^{\circledR}$, primeiro medicamento oral lançado no mercado para tratamento da disfunção erétil. É um inibidor seletivo da enzima fosfodiesterase tipo 5 (PDE5), ${ }^{2}$ o qual age restaurando a função erétil resultando em uma resposta natural à estimulação sexual.<smiles>CCCc1nn(C)c2c(=O)[nH]c(-c3cc(OS(=O)(=O)N4CCN(C)CC4)ccc3OC)nc12</smiles>

Figura 1. Estrutura química do citrato de sildenafil (Viagra $\left.{ }^{\circledR}\right)$

Viagra ${ }^{\circledR}$ rapidamente tornou-se um dos medicamentos mais populares e amplamente utilizados no tratamento da disfunção erétil. ${ }^{3}$ Paralelamente ao crescimento do seu consumo houve um aumento do número de casos de adulteração e falsificação deste medicamento. ${ }^{4}$ Até o presente momento, há uma ausência de monografia e descrição de método oficial para sua análise na farmacopéia brasileira e nas principais obras internacionais desta categoria. Diante dessas considerações, é de suma importância garantir a qualidade dos produtos comercializados para a proteção da saúde dos consumidores.

As técnicas descritas na literatura para análise de citrato de sildenafil incluem voltametria, ${ }^{5,6}$ cromatografia líquida de alta eficiência com detecção $\mathrm{UV}^{7-9}$ ou acoplada à espectrometria de massa, ${ }^{10}$ cromatografia eletrocinética micelar, ${ }^{11}$ cromatografia gasosa, ${ }^{12}$

*e-mail: hrpezza@iq.unesp.br eletroforese capilar, ${ }^{13}$ espectroscopia de ressonância magnética nuclear $^{14}$ e espectrofotometria. ${ }^{15-17}$ Os métodos cromatográficos são os mais empregados na determinação de citrato de sildenafil em várias matrizes (formulações farmacêuticas, plasma e urina), ${ }^{7-9,11}$ bem como na determinação de parâmetros farmacocinéticos. Estes possuem limites de detecção baixos o que justifica seu emprego na análise de fluidos biológicos. Entretanto, requerem um longo tempo nas etapas iniciais de preparo das amostras, utilizam maiores quantidades de solventes e a instrumentação é mais dispendiosa, o que eleva o custo final das análises. Para a análise de formulações farmacêuticas, é desejável que métodos utilizando técnicas de baixo custo e que forneçam resultados rápidos, precisos e exatos estejam disponíveis.

A espectrofotometria de absorção molecular é a técnica instrumental de escolha largamente utilizada para essa finalidade possuindo as vantagens de ser simples, envolver o uso de equipamento de baixo custo e poder ser facilmente automatizada. São escassos os métodos descritos na literatura para a determinação de citrato de sildenafil por espectrofotometria ${ }^{15-17}$ e estes apresentam algumas desvantagens, pois requerem aquecimento para o desenvolvimento de cor em meio de acetonitrila ${ }^{16}$ ou envolvem procedimentos laboriosos com muitas etapas de manipulação das amostras, incluindo extrações com clorofórmio. ${ }^{15}$

Este trabalho descreve o desenvolvimento de um método espectrofotométrico rápido e simples baseado na reação entre citrato de sildenafil e p-cloranil ${ }^{16}$ acelerada pela adição de peróxido de hidrogênio, produzindo instantaneamente um complexo estável de cor violeta $\left(\lambda_{\max }=535 \mathrm{~nm}\right)$ a temperatura ambiente.

\section{PARTE EXPERIMENTAL}

\section{Materiais e equipamentos}

As medidas de volume foram efetuadas com buretas classe A ou micropipeta Eppendorf (100-1000 $\mu \mathrm{L})$. A vidraria utilizada no preparo das soluções foi de grau A e as pesagens foram realizadas em balança analítica AG204, Mettler Toledo. As medidas de absorbância foram efetuadas em espectrofotômetro Varian modelo Cary 100 munido de cubetas de vidro ou quartzo com caminho ótico de $1 \mathrm{~cm}$. 


\section{Reagentes e soluções}

Todos os reagentes e solventes empregados neste trabalho foram de grau analítico. Solução de trabalho $5,68 \times 10^{-3} \mathrm{~mol} \mathrm{~L}^{-1} \mathrm{de}$ citrato de sildenafil (fornecido pela Pfizer, 95\%) foi preparada em metanol (Mallinckrodt, Xalostoc, México). Esta solução é estável por 15 dias se conservada em geladeira. ${ }^{5}$ p-cloranil (Sigma, St. Louis, EUA), solução de trabalho $1,00 \times 10^{-2} \mathrm{~mol} \mathrm{~L}^{-1}$ de p-cloranil (Sigma, St. Louis, EUA) foi preparada em dioxano (Mallinckrodt, Xalostoc, México). Solução de peróxido de hidrogênio 5,00 mol $\mathrm{L}^{-1}$ foi preparada pela adequada diluição da solução de Peridrol (Merck, Darmstadt, Germany, 30\% m/m) com metanol, previamente padronizada de acordo com o procedimento permanganimétrico. ${ }^{18}$

\section{Procedimento recomendado}

\section{Construção da curva analítica}

Para a construção da curva analítica foram adicionados a balões volumétricos de $5 \mathrm{~mL}: 640 \mu \mathrm{L}$ de p-cloranil $\left(1,00 \times 10^{-2} \mathrm{~mol}\right.$ $\left.\mathrm{L}^{-1}\right) ; 330 \mu \mathrm{L}$ de $\mathrm{H}_{2} \mathrm{O}_{2}\left(5,00 \mathrm{~mol} \mathrm{~L}^{-1}\right)$ e alíquotas de 0,075 a $1,50 \mathrm{~mL}$ de citrato de sildenafil $\left(5,68 \times 10^{-3} \mathrm{~mol} \mathrm{~L}^{-1}\right)$, de modo que sua concentração final variou de $8,52 \times 10^{-5}$ a $1,70 \times 10^{-3} \mathrm{~mol} \mathrm{~L}^{-1}$. Completou-se o volume dos balões com metanol até a marca e em seguida efetuou-se as medidas de absorbância em $535 \mathrm{~nm}$ contra um branco preparado similarmente, porém sem adição de citrato de sildenafil. Construiu-se a curva de calibração traçando-se o gráfico dos valores de absorbância medidos em função da concentração de citrato de sildenafil.

\section{Preparo e análise das amostras}

As amostras de medicamentos contendo citrato de sildenafil disponíveis no mercado foram adquiridas em farmácias locais e analisadas pelo método proposto, dentro dos seus prazos de validade.

Dezesseis comprimidos, de um mesmo lote, foram pesados em balança analítica e determinou-se o valor da massa média. Subseqüentemente, os mesmos foram pulverizados em gral de ágata até obtenção de um pó fino. Uma porção de amostra pulverizada equivalente a $20 \mathrm{mg}$ de citrato de sildenafil foi exatamente pesada e submetida à agitação com $5 \mathrm{~mL}$ de metanol em agitador magnético por 15 min. Esta solução foi transferida para balão volumétrico de $10 \mathrm{~mL}$ e o volume completado com metanol até o menisco. Na sequiência, a solução foi filtrada em papel de filtro quantitativo Whatman 41 e uma alíquota de $750 \mu \mathrm{L}$ foi tomada e analisada de acordo com o procedimento recomendado para a construção da curva analítica.

\section{RESULTADOS E DISCUSSÃO}

A interação molecular entre doador-receptor de elétrons está normalmente associada com a formação de complexos de transferência de carga, intensamente coloridos. ${ }^{19-21}$ Dentre os receptores de elétrons comumente utilizados no desenvolvimento de métodos espectrofotométricos baseados na formação destes complexos, está o p-cloranil.

Dados da literatura revelam que as reações com p-cloranil são normalmente lentas a temperatura ambiente, sendo necessário aquecimento a $60-65{ }^{\circ} \mathrm{C}$ durante $10-45$ min para que a reação ocorra. A reação entre citrato de sildenafil e p-cloranil em meio de acetonitrila requer aquecimento a $60{ }^{\circ} \mathrm{C}$ durante $10 \mathrm{~min}$ para que haja o desenvolvimento de cor. ${ }^{16}$ Nenhuma menção sobre a cinética e estabilidade do produto formado é fornecida no referido artigo. Tentativas de análise utilizando este método, em condições idênticas às descritas na literatura, revelaram ausência de reprodutibilidade.
Experimentos preliminares realizados em nosso laboratório revelaram que na presença de peróxido de hidrogênio a reação é marcadamente acelerada, com formação rápida de um produto estável de cor violeta. Na ausência de peróxido a reação é demasiadamente lenta. No melhor do nosso conhecimento, há somente um método descrito na literatura que envolve o uso de peróxido de hidrogênio como acelerador da reação de transferência de carga com p-cloranil, o qual foi desenvolvido em nosso laboratório e aplicado na determinação de sacarina. ${ }^{22}$

Um estudo inicial foi feito para selecionar o meio reacional mais adequado para o desenvolvimento da reação na presença de peróxido de hidrogênio. Foram testados acetona, acetonitrila e dioxano como solvente para a dissolução do p-cloranil e metanol, acetona, acetonitrila e dioxano para ajuste do volume dos balões. Metanol não foi utilizado no preparo da solução de p-cloranil devido à baixa solubilidade do composto neste solvente. Obteve-se melhor sensibilidade e maior estabilidade óptica do produto colorido quando a reação foi executada com solução de p-cloranil preparada em dioxano e o volume dos balões completado com metanol.

O espectro de absorção do produto colorido formado após a reação entre citrato de sildenafil e p-cloranil, na presença e na ausência de $\mathrm{H}_{2} \mathrm{O}_{2}$, é apresentado na Figura 2.

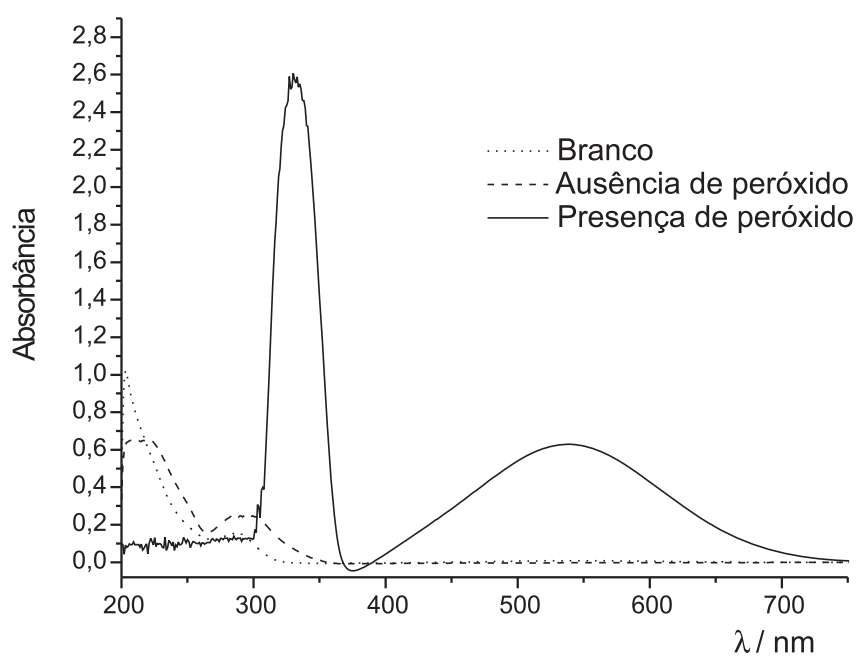

Figura 2. Espectro de absorção do produto da reação na presença e na ausência de peróxido. Concentrações finais: citrato de sildenafil 1,70 × 10-3 mol L $L^{-1}$, p-cloranil $3,15 \times 10^{-3} \mathrm{~mol} \mathrm{~L}^{-1}$ e $\mathrm{H}_{2} \mathrm{O}_{2} 0,33$ mol L-1, em meio de metanol/ dioxano $(4,36 / 0,64)$. Caminho óptico $=1 \mathrm{~cm}$

A literatura descreve que o p-cloranil pode interagir com moléculas contendo centros doadores de elétrons segundo dois tipos de reações, sendo uma delas baseada na formação de uma aminoquinona mono-substituída (Esquema 1a) e a outra, através da formação de um complexo de transferência de carga com subseqüente dissociação do mesmo em solvente polar formando par iônico radicalar $^{21,23}$ (Esquema 1b).

Com base nesse relato ${ }^{21,23}$ e em testes qualitativos realizados em nosso laboratório supomos que a reação predominante entre citrato de sildenafil, e p-cloranil na presença de peróxido de hidrogênio consiste na formação de uma amino-quinona substituída. Nesse caso, o peróxido provavelmente estaria atuando na oxidação do citrato de sildenafil que então reage com o p-cloranil formando o produto de substituição. Esta consideração foi fundamentada na obtenção de teste positivo para cloreto (em meio de ácido nítrico) realizado com o produto da reação, cuja formação só ocorre em reações de substituição. Além disso, o espectro UV-Vis do produto colorido obtido, com máximos de absorção em 535 e 330 nm é 
a) $\mathrm{R}_{2} \mathrm{NH}$<smiles>O=C1C(Cl)=C(Cl)C(=O)C(Cl)=C1Cl</smiles><smiles>C1CCCCC1</smiles><smiles>[R10]C1=C(Cl)C(=O)C(Cl)=C(Cl)C1=O</smiles>

Amino-quinona (produto de substituição)

b)<smiles>[R2]N[CH]N[NH+][R]</smiles>

Par iônico-radicalar

Esquema 1. Reações propostas na literatura ${ }^{21,23}$ para a interação entre aminas e p-cloranil: a) reação de substituição; b) reação com formaçãa de um complexo de transferência de carga

muito similar ao espectro de amino-quinonas mono-substituídas. ${ }^{21}$ Já o íon radical formado pela dissociação do complexo de transferência de carga com o p-cloranil apresenta máximos de absorção em torno de 440-450 nm. ${ }^{21}$

Para as medidas espectrofotométricas selecionou-se o comprimento de onda situado na região visível do espectro, embora menos sensível que o situado na região UV, visto que na região ultravioleta as medidas estão sujeitas a interferências já que a maioria dos compostos orgânicos apresenta absorção nesta região.

Uma vez que o dioxano demonstrou ser o melhor solvente para a dissolução do p-cloranil e sabendo-se que este pode conter traços de peróxido, foi necessário determinar o teor de $\mathrm{H}_{2} \mathrm{O}_{2}$ presente no dioxano utilizado no desenvolvimento do método proposto. Para tal, foi empregado o método espectrofotométrico modificado descrito por Benatsky e Tomik ${ }^{24}$ para determinação de peróxidos em solventes orgânicos. Os resultados obtidos revelaram que o dioxano analisado continha $4,71 \times 10^{-4} \mathrm{~mol} \mathrm{~L}^{-1}$ de $\mathrm{H}_{2} \mathrm{O}_{2}$, valor este menor que aquele descrito nas especificações do rótulo que é de $1,47 \times 10^{-3} \mathrm{~mol} \mathrm{~L}^{-1}$.

\section{Otimização da metodologia proposta}

O procedimento tradicional para otimização de forma univariada, onde cada fator é avaliado separadamente, envolve um grande número de experimentos e não fornece informações de como cada fator se comporta frente aos demais. A forma mais eficiente de se extrair uma maior quantidade de informações sobre um determinado sistema com um número mínimo de ensaios é a utilização de ferramentas estatísticas de planejamento de experimentos. Na prática isso significa diminuição de horas trabalhadas, de gastos com reagentes e mais agilidade no desenvolvimento de novos produtos, processos ou métodos. ${ }^{25}$

Neste trabalho a metodologia de superfície de resposta foi empregada na otimização do procedimento, utilizando um planejamento composto central. O objetivo foi obter a melhor condição experimental na qual se obtém um valor ótimo para a variável resposta (medida de absorbância em $535 \mathrm{~nm}$ ), ou seja, é possível ob- ter melhor sensibilidade analítica.

Neste planejamento a variação na absorbância foi investigada em função das variáveis $\left(\xi_{i}\right)$ : volume de p-cloranil e volume de peróxido de hidrogênio, uma vez que o solvente já havia sido selecionado. As variáveis $\left(\xi_{i}\right)$ consideradas com seus níveis examinados (reais e codificados) e a matriz experimental com os resultados obtidos estão mostradas na Tabela 1. Os experimentos no ponto central foram realizados em replicatas $(n=4)$ para estimativa do erro experimental e os resultados foram analisados utilizando o programa Statistica, versão 6.0. Para cada variável $\left(\xi_{i}\right)$ o valor real de $\mathrm{x}_{\mathrm{i}}$ (nível codificado por $-1,41 ;-1,0,+1$ e $+1,41$ ) é determinado de acordo com a Equação $1 .^{26}$

$x_{i}=2\left(\xi_{i}-\xi_{i}^{*}\right) / d_{i}$

onde, $\xi_{i}$ é o valor real da variável, $\xi_{i}^{*}$ é a média aritmética dos níveis alto (+1) e baixo (-1) da variável $\xi_{i}$ e $\mathrm{d}_{i}$ é a diferença entre os níveis alto e baixo de $\xi_{i}$.

Tabela 1. Matriz experimental do planejamento composto central

\begin{tabular}{|c|c|c|c|c|c|}
\hline \multirow[t]{2}{*}{ Ensaio } & \multicolumn{2}{|c|}{$\begin{array}{l}\text { Variáveis não } \\
\text { codificadas } \\
\text { em seus níveis }\end{array}$} & \multicolumn{2}{|c|}{$\begin{array}{l}\text { Variáveis } \\
\text { codificadas } \\
\text { em seus níveis }\end{array}$} & \multirow[t]{2}{*}{$\mathrm{A}_{535 \mathrm{~nm}}$} \\
\hline & $\mathrm{V}_{\mathrm{p} \text {-cloranil }}(\mu \mathrm{L})^{\mathrm{a}}$ & $\mathrm{V}_{\text {peróxido }}(\mu \mathrm{L})^{\mathrm{b}}$ & Fator A & Fator B & \\
\hline 1 & 210 & 195 & -1 & -1 & 0,3084 \\
\hline 2 & 780 & 195 & 1 & -1 & 0,5120 \\
\hline 3 & 210 & 650 & -1 & 1 & 0,3715 \\
\hline 4 & 780 & 650 & 1 & 1 & 0,4432 \\
\hline $5^{c}$ & 495 & 420 & 0 & 0 & 0,5219 \\
\hline $6^{c}$ & 495 & 420 & 0 & 0 & 0,5186 \\
\hline $7^{c}$ & 495 & 420 & 0 & 0 & 0,5148 \\
\hline $8^{c}$ & 495 & 420 & 0 & 0 & 0,5121 \\
\hline 9 & 100 & 420 & $-1,41$ & 0 & 0,2003 \\
\hline 10 & 890 & 420 & 1,41 & 0 & 0,4379 \\
\hline 11 & 495 & 100 & 0 & $-1,41$ & 0,4588 \\
\hline 12 & 495 & 740 & 0 & 1,41 & 0,4182 \\
\hline
\end{tabular}

${ }^{a}$ p-cloranil 1,00 x 10-2 $\mathrm{mol} \mathrm{L}^{-1}$ (preparado em dioxano); ${ }^{\mathrm{b}} \mathrm{H}_{2} \mathrm{O}_{2} 5,00$ mol L ${ }^{-1}$; ${ }^{c}$ Ponto central executado em replicatas $(n=4)$.

Os resultados obtidos a partir deste planejamento (Tabela 1) foram ajustados a um modelo matemático quadrático descrito pela Equação 2, utilizando o programa Statistica, versão 6.0. A superfície de resposta e a curva de nível correspondente ao modelo ajustado estão representadas na Figura 3.

$\mathbf{Z}=-9,7 \times 10^{-2}+1,6 \times 10^{-2} \mathbf{x}-1,0 \times 10^{-6} \mathbf{x}^{2}+$

A Equação 2 inclui os termos lineares ( $\mathbf{x}$ e $\mathbf{y})$ e quadráticos $\left(\mathbf{x}^{2}\right.$ e $\mathbf{y}^{2}$ ) bem como o produto dos pares dos efeitos lineares (xy). Nesta equação, $\mathbf{Z}$ representa a absorbância em $535 \mathrm{~nm}$, e as variáveis $\mathbf{x}$ e y são volumes de p-cloranil e de $\mathrm{H}_{2} \mathrm{O}_{2}$, respectivamente.

A análise da Figura 3 indica que dentro do intervalo em que as variáveis independentes foram avaliadas, o valor da variável dependente passa por uma região de máximo, situada na área mais escura do gráfico, a qual representa a condição experimental ótima para a realização da reação proposta. De acordo com estes resultados, os maiores valores de absorbância foram obtidos quando os volumes adicionados de p-cloranil $\left(1,00 \times 10^{-2} \mathrm{~mol} \mathrm{~L}^{-1}\right)$ e de $\mathrm{H}_{2} \mathrm{O}_{2}$ $\left(5,00 \mathrm{~mol} \mathrm{~L}^{-1}\right)$ foram 640 e $330 \mu \mathrm{L}$, respectivamente. 


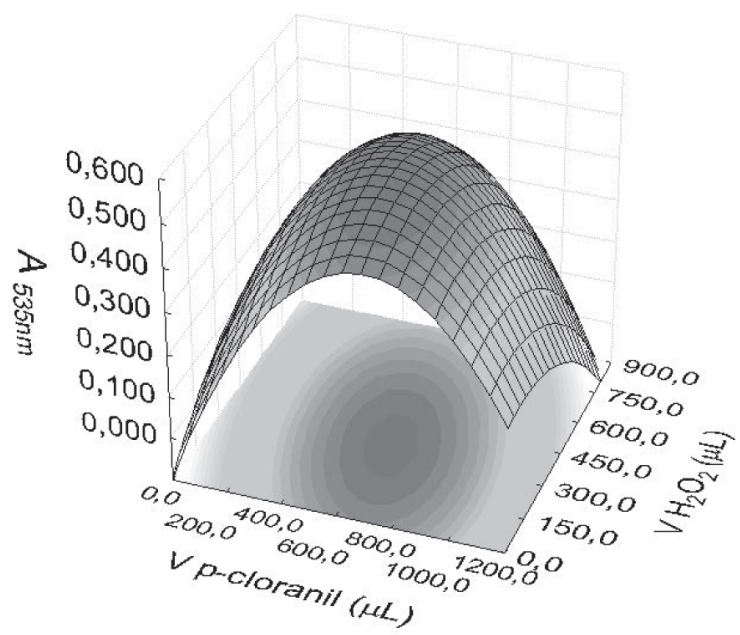

Figura 3. Superfície de resposta otimizada para a absorbância $(\lambda=535 \mathrm{~nm})$ em função das variáveis independentes: volume de p-cloranil (1,00 × 10-2 mol $\left.\mathrm{L}^{-1}\right)$ e volume de $\mathrm{H}_{2} \mathrm{O}_{2} 5,00 \mathrm{~mol} \mathrm{L^{-1 }}$. A concentração final de citrato de sildenafil foi mantida constante $\left(1,13 \times 10^{-3} \mathrm{~mol} \mathrm{~L}^{-1}\right)$ em todos os experimentos

\section{Verificação da linearidade}

Após a otimização das condições experimentais verificou-se a faixa de trabalho onde uma relação linear entre o valor de absorbância medido e a concentração de citrato de sildenafil era obtida. Construiu-se a curva analítica representando os valores de $\mathrm{A}_{535 \mathrm{~nm}}$ em função da concentração de citrato de sildenafil. Uma relação linear foi observada na faixa de concentração de $8.52 \times 10^{-5} \mathrm{~mol}$ $\mathrm{L}^{-1}$ a $1,70 \times 10^{-3} \mathrm{~mol} \mathrm{~L}^{-1}$.

A equação matemática que descreve a relação linear existente entre $A_{535 \mathrm{~nm}}$ e concentração de citrato de sildenafil é: $\mathrm{A}_{535 \mathrm{~nm}}=0,0316$ $( \pm 0,0051)+487,2( \pm 4,65) \times C$, onde $\mathrm{C}=$ concentração de citrato de sildenafil em mol L-1, com um coeficiente de correlação de 0,999 .

\section{Estudo da estabilidade óptica}

Neste estudo o valor da medida de absorbância em $535 \mathrm{~nm}$ foi monitorado em intervalos de $10 \mathrm{~min}$ durante $1 \mathrm{~h}$. O produto colorido formado permaneceu estável por pelo menos $1 \mathrm{~h}$.

\section{Estudo de interferentes}

$\mathrm{O}$ efeito de cada excipiente (celulose microcristalina, fosfato de cálcio dibásico anidro, estearato de magnésio, metilcelulose hidroxipropil, dióxido de titânio, lactose e croscarmelose sódica) foi considerado como interferência quando o sinal de absorbância apresentou erro maior ou igual a $5 \%$ na determinação do fármaco. ${ }^{27} \mathrm{~A}$ porcentagem de citrato de sildenafil encontrada nas soluções adicionadas foi de 98,6 a 101,5\%, com coeficientes de variação menores que $3 \%$ para três repetições. Assim, nenhuma interferência foi constatada a partir destes excipientes, sob as condições estudadas.

\section{Aplicações analíticas e validação do método proposto}

O método desenvolvido foi aplicado na determinação de citrato de sildenafil em duas formulações farmacêuticas disponíveis no mercado. Os resultados obtidos pela aplicação do método proposto são apresentados na Tabela 2.

Para validação do método desenvolvido foram avaliados alguns parâmetros considerados importantes, tais como exatidão, preci-

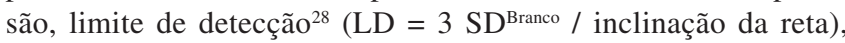

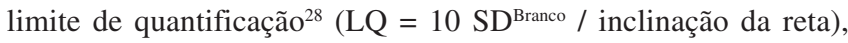
sensibilidade analítica, ${ }^{29}$ recuperação e repetibilidade.

A precisão e exatidão do método proposto foram avaliadas através da aplicação dos testes $\mathrm{F}$ e t, respectivamente. Os resultados obtidos
Tabela 2. Determinação de citrato de sildenafil em formulações farmacêuticas

\begin{tabular}{|c|c|c|c|c|c|c|}
\hline \multirow[t]{2}{*}{ Amostras } & \multicolumn{2}{|c|}{$\begin{array}{l}\text { Método } \\
\text { proposto }\end{array}$} & \multirow{2}{*}{$\begin{array}{c}\mathrm{t}^{\mathrm{d}} \\
(2,78)\end{array}$} & \multirow{2}{*}{$\begin{array}{c}\mathrm{F}^{\mathrm{d}} \\
(19,00)\end{array}$} & \multicolumn{2}{|c|}{$\begin{array}{c}\text { Método } \\
\text { comparativo }^{15}\end{array}$} \\
\hline & Médiaa ${ }^{\mathrm{a}, \mathrm{b}}$ & R.S.D. ${ }^{c}$ & & & Média $^{\mathrm{a}, \mathrm{b}}$ & R.S.D. ${ }^{\mathrm{c}}$ \\
\hline A & 49,9 & $0,6 \%$ & 0,11 & 1,78 & 50,0 & $0,8 \%$ \\
\hline $50,00 \mathrm{mg}$ & $\pm 0,3$ & & & & $\pm 0,4$ & \\
\hline B & 99,5 & $0,9 \%$ & 1,72 & 1,65 & 100,6 & $0,6 \%$ \\
\hline $100,00 \mathrm{mg}$ & $\pm 0,9$ & & & & $\pm 0,7$ & \\
\hline
\end{tabular}

${ }^{\mathrm{a}} \mathrm{mg}$ por comprimido; ${ }^{\mathrm{b}} \mathrm{n}=3$; ${ }^{\mathrm{c}}$ Desvio padrão relativo; ${ }^{\mathrm{d}}$ Valor tabelado com $\mathrm{P}=0.05-95 \%$ de significância

pelo método proposto foram comparados com aqueles obtidos pela aplicação de um método espectrofotométrico descrito na literatura. ${ }^{15}$ Para as duas amostras analisadas os valores obtidos pelo método proposto mostraram-se em boa concordância com os obtidos pelo método de comparação. Os valores de $\mathrm{F}$ e $\mathrm{t}$ calculados não excederam os valores tabelados, indicando desta forma a precisão e exatidão do método desenvolvido, com um nível de confiança de $95 \%$.

Para a avaliação da precisão intradia foram realizadas análises em replicatas $(n=10)$ para soluções de uma mesma amostra contendo o equivalente a $8,50 \times 10^{-4} \mathrm{~mol} \mathrm{~L}^{-1}$ de citrato de sildenafil e para o estudo da precisão interdia foram executadas análises da amostra durante um período de 5 dias consecutivos. Os resultados obtidos, em termos de coeficiente de variação, foram de 0,9 e 1,1\%, evidenciando a boa repetibilidade do método desenvolvido.

Os limites de detecção (LD) e de quantificação (LQ) foram calculados de acordo com as recomendações da IUPAC ${ }^{28}$ como sendo $1,96 \times 10^{-5} \mathrm{~mol} \mathrm{~L}^{-1}$ e $6,52 \times 10^{-5} \mathrm{~mol} \mathrm{~L}^{-1}$, respectivamente. A sensibilidade analítica foi estimada ${ }^{29}$ como sendo de $1,53 \times 10^{5} \mathrm{~L}$ $\mathrm{mol}^{-1}$. O inverso da sensibilidade analítica fornece a diferença de concentração mínima que é discernível pelo método analítico, na ausência de erro experimental. Para o método proposto o valor estimado foi de $6,53 \times 10^{-6} \mathrm{~mol} \mathrm{~L}^{-1}$.

Estudos de recuperação foram realizados através do método da adição de padrão. ${ }^{30}$ Neste estudo, quantidades conhecidas de citrato de sildenafil (padrão analítico) foram adicionadas às duas amostras pré-analisadas. De acordo com os resultados obtidos apresentados na Tabela 3, observa-se que as médias porcentuais de recupe-

Tabela 3. Resultados de recuperação de citrato de sildenafil adicionado às formulações farmacêuticas pré-analisadas

\begin{tabular}{lcccr}
\hline Amostra $^{\mathrm{a}}$ & $\begin{array}{c}\text { [Citrato de } \\
\text { sildenafil] } \\
\text { adicionada } \\
(\mathrm{ppm})\end{array}$ & $\begin{array}{c}\text { [Citrato de } \\
\text { sildenafil] } \\
\text { encontrada }^{\mathrm{a}} \\
(\mathrm{ppm})\end{array}$ & R.S.D. $^{\mathrm{b}}$ & $\begin{array}{c}\% \\
\text { recuperação }^{\mathrm{a}}\end{array}$ \\
\hline A & 0 & - & - & - \\
$50,0 \mathrm{mg}$ & 100,0 & $399,0 \pm 2,4$ & 0,6 & $99,0 \pm 2,3$ \\
& 200,0 & $400,0 \pm 4,3$ & 1,1 & $100,5 \pm 2,1$ \\
& 300,0 & $497,9 \pm 0,8$ & 0,2 & $99,6 \pm 0,3$ \\
& 400,0 & $596,5 \pm 1,8$ & 0,3 & $99,4 \pm 0,3$ \\
& 500,0 & $704,2 \pm 4,5$ & 0,6 & $101,1 \pm 0,9$ \\
\hline B & 0 & - & - & - \\
& $100,0 \mathrm{mg}$ & $298,5 \pm 2,6$ & 0,9 & $99,0 \pm 2,6$ \\
& 200,0 & $401,0 \pm 4,9$ & 1,2 & $100,7 \pm 2,4$ \\
& 300,0 & $503,8 \pm 2,5$ & 0,5 & $101,4 \pm 0,8$ \\
& 400,0 & $601,0 \pm 5,5$ & 0,9 & $100,4 \pm 1,4$ \\
& 500,0 & $707,9 \pm 5,1$ & 0,7 & $101,7 \pm 1,4$ \\
\hline
\end{tabular}

${ }^{a}$ Média de 3 determinações; ${ }^{\mathrm{b}}$ desvio padrão relativo 
ração de citrato de sildenafil encontram-se entre 99,0-101,7\%, evidenciando novamente a boa exatidão do método proposto, além de mostrar a ausência de interferência significativa de matriz.

\section{CONCLUSÕES}

O método desenvolvido é simples, rápido, fácil de ser executado, apresenta ótima sensibilidade analítica $\left(1,53 \times 10^{5} \mathrm{~mol}^{-1} \mathrm{~L}\right)$, não requer etapas de pré-tratamento da amostra e apresenta baixo consumo de reagentes $(1,57 \mathrm{mg}$ de p-cloranil e $330 \mu \mathrm{L}$ de solução de $\mathrm{H}_{2} \mathrm{O}_{2} 5,00 \mathrm{~mol} \mathrm{~L}^{-1}$ por amostra analisada). O método foi aplicado com sucesso na determinação de citrato de sildenafil em formulações farmacêuticas, com excelentes resultados em termos de precisão e exatidão, sendo uma boa alternativa para a determinação de citrato de sildenafil em formulações farmacêuticas com resultados de elevada confiabilidade.

\section{AGRADECIMENTOS}

Ao Conselho Nacional de Desenvolvimento Científico e Tecnológico $(\mathrm{CNPq})$ e à Fundação de Amparo à Pesquisa do Estado de São Paulo (FAPESP) pelo apoio financeiro. À indústria Pfizer pelo fornecimento do princípio ativo (citrato de sildenafil).

\section{REFERENCIAS}

1. The Merck Index. An Encyclopedia of Chemicals, Drugs and Biologicals, $13^{\text {rd }}$ ed., Merck \& Co. Inc.: New Jersey, 2001.

2. Cooper, J. D. H.; Muirhead, D. C.; Taylor, J. E.; Baker, P. R.; J. Chromatogr, B: Anal. Technol. Biomed. Life Sci. 1997, 701, 87.

3. Nagaraju, V.; Sreenath, D.; Rao, J. T.; Rao, R. N.; Anal. Sci. 2003, 19, 1007.

4. h t t p : / / e-legis.anvis a.gov.br/leis ref/public/ showAct.php?id=21808\&word=viagra, acessada em Maio 2007.

5. Rodriguez, J.; Berzas, J. J.; Castaneda, G.; Rodriguez, N.; Talanta 2004, $62,427$.
6. Ozkan, S. A.; Uslu, B.; Zuman, P.; Anal. Chim. Acta 2004, 501, 227.

7. Dinesh, N. D.; Vishukumar, B. K.; Nagaraja, P.; Gowda, N. M. M.; Rangappa, K. S.; J. Pharm. Biomed. Anal. 2002, 29, 743.

8. Aboul-Enein, H. Y.; Hefnawy, M. M.; J. Liq. Chromatogr. Relat. Technol. 2003, 26, 2897.

9. Ergun, B.; Saracoglu, A.; Ilgin, S.; Atkosar, Z.; Kircali, K.; Altiokka, G.; J. Liq. Chromatogr. Relat. Technol. 2005, 28, 1539.

10. Zhu, X. L.; Xiao, S.; Chen, B.; Zhang, F.; Yao, S. Z.; Wan, Z. T.; Yang, D. J.; Han, H. W.; J. Chromatogr., A 2005, 1066, 89.

11. Nevado, J. J. B.; Flores, J. R.; Penalvo, G. C.; Farinas, N. R.; J. Chromatogr., A 2002, 953, 279.

12. Berzas, J. J.; Rodriquez, J.; Villasenor, M. J.; Contento, A. M.; Cabello, M. P.; Chromatographia 2002, 55, 601.

13. Qin, W.; Li, S. F. Y.; Electrophoresis 2002, 23, 4110

14. Wawer, I.; Pisklak, M.; Chilmonczyk, Z.; J. Pharm. Biomed. Anal. 2005, 38,865 .

15. Dinesh, N. D.; Nagaraja, P.; Gowda, N. M. M.; Rangappa, K. S.; Talanta 2002, 57, 757

16. Amin, A. S.; El-Beshbeshy, A. M.; Microchim. Acta 2001, 137, 63.

17. Kuchekar, B. S.; Thakkar, S. V.; Chothe, P. P.; Hiremath, M. R.; Shinde, D. B.; Indian J. Pharm. Sci. 2005, 67, 749.

18. Vogel, A. I.; Análise Inorgânica Quantitativa, 4⿳亠丷厂 ed., Guanabara Dois: Rio de Janeiro, 1981.

19. Abdellatef, H. E.; J. Pharm. Biomed. Anal. 1998, 17, 1267.

20. Adikwu, M. U.; Ofokansi, K. C.; J. Pharm. Biomed. Anal. 1997, 16, 529.

21. Bebawy, L. I.; El-Kousy, N.; Suddik, J. K.; Shokry, M.; J. Pharm. Biomed. Anal. 1999, 21, 133.

22. Weinert, P. L.; Pezza, H. R.; Oliveira, J. E.; Pezza, L.; J. Agric. Food Chem. 2004, 52, 7788.

23. Smith, R. E.; Davis, W.; Anal. Chem. 1984, 56, 2345.

24. Benatsky, M.; Tomik, B.; Chem. Listy 1988, 82, 759 (CA: 109:221642).

25. Barros, B, N.; Scarminio, I. S.; Bruns, R. E.; Como fazer experimentos: pesquisa e desenvolvimento na ciência e na indústria, Ed. da UNICAMP: Campinas, 2001.

26. Rezzoug, S. A.; Capart, R.; Energy Conversion and Management 2003, 44 , 781 .

27. Farmacopéia Brasileira, $3^{\mathrm{a}}$ ed., Atheneu: São Paulo, 1977.

28. Long, G. L.; Winefordner, J. D.; Anal. Chem. 1983, 55, 712A

29. Rodríguez, L. C.; Campaña, A. M. G.; Linares, C. J.; Ceba, M. R.; Anal. Lett. 1993, 26, 1243.

30. Bader, M. A.; J. Chem. Educ. 1980, 57, 703 